\title{
Child psychoanalytic psychotherapy
}

\author{
M. Fitzgerald
}

The goal of psychoanalytic psychotherapy with a distressed child is to alter the child's psychic structure and function. The technique is based on the same theory as adult psychoanalytic psychotherapy (see Box 1). The unconscious is central, as is the interpretation of defence, resistance, transference, working through and the reconstruction of earlier life. It differs from adult psychotherapy in that the child's age and level of development are at all times central to the work. In young children the focus of interpretation is on free play, while with adults it is free association of ideas. In the treatment of adolescents a combination of techniques, both adult and pre-adolescent, are used, while for late adolescents the technique is basically adult technique with attention to issues relevant to that stage of the life cycle.

\section{Modern psychoanalysis}

Modern psychoanalysis has expanded our understanding of children and adolescents, as Sigmund Freud's original model was excessively reductionistic and could not deal with the full complexity of human behaviour. Nevertheless, many of Freud's fundamental tenets, for example the importance of the unconscious, still hold as well as the clinical

\section{Box 1. Child versus adult psychotherapy}

Child psychotherapy shares many similarities with adult psychotherapy - the unconscious, transference, resistance, etc. but differs in its emphasis on the child's age, level of development as well as free play being a focus of interpretation. concepts of transference, countertransference, working alliance and negative therapeutic reaction.

Since Freud, multiple psychoanalytic paradigms have developed, including Kleinian psychology and self-psychology. While Freud emphasised an energy discharge point of view within a natural science framework, more recent work has also stressed a 'person' point of view within a hermeneutic framework (see Box 2). The two points of view help us to understand different aspects of psychoanalysis. The energy discharge model can be helpful in partially understanding obsessional neurosis, as indeed will increased knowledge of genetics, while the person-oriented model can give us some help in understanding borderline personality disorders (American Psychiatric Association, 1994). Further work needs to be done in reconciling these two approaches.

John Bowlby's work on attachment, separation and loss has implications for psychoanalysis. His concept of the secure base for the child in relation to the mother would appear to describe usefully the relationship of the child to the child psychotherapist. John Bowlby was critical of psychoanalytic explanations of psychic energy and drive discharge. He proposed explanations in terms of attachment and emphasised systems theory, information theory and cognitive psychology. In modern psychoanalysis the emphasis has moved onto a person or human relatedness paradigm, in contrast to the body paradigm of traditional psychoanalysis. Bowlby in particular emphasised the importance of the external environment on the child and believed that much acute and chronic anxiety was due to threats of abandonment by a parent as a means of discipline. He did not give sufficient emphasis to the child's mental set and the effect of the child's personal fantasies in processing the external stress. The modern child psychotherapist has to give due weight to internal and external factors.

Michael Fitzgerald (Child and Family Centre, Ballyfermot Road (Beside Health Centre) Dublin 10, Republic of Ireland) is an Associate Member of the British Psychoanalytical Society, and is interested in all aspects of psychotherapy, including outcome research. 
The new directions in psychoanalysis focus on interpersonal interactions with a detailed study of the interplay between the psyche of the person and the therapist. This is a two-person psychological model, therefore there is less focus on drive discharge and of the person unveiling themself, than in the one-person psychological model. The focus is no longer on so-called therapist neutrality but on building up new meanings with the person. They work together in the new model. The therapist cannot help but reveal himself through his interventions and within this 'bipersonal field'; therefore, the psychotherapeutic dialogue is the outcome of both parties and not just the product of the person. The therapist's interpretation emerges from reviewing his/her own thoughts, feelings and the person's input, whether verbal or non-verbal. The newer models of psychoanalysis posit people as seeking human contact, and psychopathology is seen as a result of relational failure. All psychoanalytic treatments are research because each person brings something unique that has not been exactly described previously and which the therapist has to work with in a creative way without imprisoning himself in some theoretical model that does not fit with the individual.

The more recent advances in psychoanalytic theory and technique have led to better modes of treatment with psychologically vulnerable people. Heinz Kohut pointed out that for vulnerable and 'fragmented' people the older psychoanalytic emphasis on conflict gave insufficient understanding. His self-psychology places the emphasis on the person's "experience of others as centres of initiative leading to the construction of the self" (Cohler \& Galatzer-Levy, 1988). This has led to considerable emphasis being placed on failures of parental empathy for the child leading to disorders of the self and low self-esteem. The child therapist's empathy to the child in treatment is therefore of critical importance. The older 'antiseptic' technique or indeed the newer French technique, with its excessive focus on language and inadequate focus on affect and the transference, can lead to

Box 2. Modern psychoanalysis

Modern psychoanalysis has shifted its emphasis from an energy discharge point of view within a natural science framework to a person point of view within a hermeneutic framework and the building up of meanings between therapist and patient. Due weight is now given to internal and external factors.. re-traumatisation of people. This is a good example of the danger of words (Berman et al, 1996). The approach of self-psychology avoids these pitfalls.

\section{Technique}

In the 1920s papers on child psychoanalysis based on work conducted directly with children began to be published using a modified technique with analysis of the young child's free play as well as the spoken word. Anna Freud's $(1965,1974)$ aim was to help the child understand the meaning of the symptom and to resolve it in that way rather than telling the child to give up the symptom. She kept management of the person to a minimum except where there were seriously harmful forces at work.

Anna Freud summarised her technique as follows:

"to analyse ego resistance before id content and to allow the work of interpretation to flow freely between id and ego; to proceed from surface to depth; to offer the person of the analyst as a transference object for the revival and interpretation of unconscious fantasies and attitudes" (Freud, 1965).

This remains an excellent approach to the technique of child psychotherapy. The modern child and adolescent psychotherapist has to integrate technical and theoretical developments in a way that is appropriate to the needs of a person.

Melanie Klein, the other great pioneer in this area, believed that the infant at birth had a capacity for some organisation. The most primitive organisation according to her was the paranoid-schizoid position which is characterised by splitting, projective identification and idealisation. There is a part object relationship where objects (persons) are exploited for what can be got out of them. There is a great deal of projection of aggression which leads the child to experience much persecutory anxiety. There is also primitive splitting into good and bad. These ideas are very helpful when dealing with severely 'damaged' personalities, for example, borderline personality disorder. The aim is to move the person onto the depressive position where there is an integration of love and hate and reparation with the aim of sparing the object from harm. Her technique has been criticised for its emphasis on the inborn death instinct, for premature deep interpretations of the unconscious and for excessive focus on transference interpretations and a relative neglect of external reality.

\section{Transference}

Transference occurs when feelings, attitudes and experience towards parental figures are transferred 
by the child onto the therapist in the present. As Yanof (1996) points out the "transference has a central place in child analysis as it does in adult analysis". Another part of the relationship involves the therapist as a new real relationship. The therapist pays attention to both. Klein (1932) used classical adult technique and interpreted play as an equivalence to free association of ideas in the adult. She emphasised the importance of analysing the child's negative ideas about the therapist and pointed out that a child could develop a transference neurosis equivalent to that of adults. It took Anna Freud many years while treating children to come to the conclusion that they could develop a transference neurosis similar to adults. Although it is possible to provide a manualised approach for the beginner, the experienced practitioner will integrate the various theories of psychoanalysis cohesively and apply them in a way that best meets the needs of the individual. All child psychotherapists will need supervision from time to time throughout their lives as part of continuing professional development.

\section{Defence}

Children often show defence activity in a nonverbal way. They may move away from the therapist, cut short a game or hide a drawing. These can be a defence against some unpleasant feeling or instinctual drive (Yanof, 1996). In the early years of psychoanalysis only the id derivative (for example, aggression) would be interpreted. However, currently these defences would also be considered much more in the context of the relationship with the therapist. That is, hiding the drawing because the child was fearful of criticism by the therapist who in the transference could represent a critical mother or father, or to protect the therapist from evidence of the child's aggression.

\section{Theory of mind}

There has been enormous interest in children's theories of mind in the past decade. This is of relevance to child psychotherapy and interventions. There is still a question as to whether children under the age of five or six years are able to 'understand' the therapist's interpretations of conflicts as expressed in play and the child's own personal worries. The gradual understanding of mind emerges between four and six years and provides

"a developmental context for considering children's capacity for internalisation, their creation of an inner psychic reality and response to therapeutic intervention" (Mayes et al, 1996).

Mayeset al (1996) also point out that

"significant for psychoanalytic work with children is the suggestion that only after children are able to understand how their own and other's mental states are constructed and how these states are behind all actions and language can they reflect upon their own thoughts and mental life".

Some therapists, especially with people with borderline personality disorder, are helping them to understand how other minds function apart from their own. Indeed, a great deal of psychotherapy is about sorting out what belongs to the child or adolescent and what belongs to other people in their environment.

\section{Importance of play}

Play is central to child analytic psychotherapy. In play children symbolise their conflicts and anxieties (Sandler et al, 1980; Segal, 1981).

During the past 10 years child psychotherapists have seen play as not only giving us an understanding of the child's mind, but also

\footnotetext{
"that play has its own development promoting function for the child inside (and outside of) the analytic setting. It raises the question of what should be interpreted directly, what interpreted in displacement and what left unsaid" (Yanof, 1996).
}

Premature interpretations can interfere with this new maturation of the child. Timing is always of critical importance; beginners tend to interpret too slowly and more experienced therapists too quickly and too frequently. When the child psychotherapist is working with the extremely deprived and ego-damaged child, as opposed to the neurotic, play can be psychologically healing and promote psychological growth in itself.

\section{Indications}

This form of treatment is useful to children who are anxious or depressed or in psychological turmoil. It is also of value to children who are in conflict because of physical illness, or who are having difficulty coming to terms with disability. It is helpful in treating children with unresolved grief reactions because of the death of a parent. These reactions can make the child more vulnerable to depression in later life if not dealt with satisfactorily. Psychoanalysis can help children who are having difficulty resolving stress due to some overwhelming trauma, for example a serious accident or other traumatic life event. 
In general, people with schizophrenia and autism would not be treated with psychoanalysis as a firstline treatment.

\section{First session}

It is not unusual for a child, coming to their first session, to have fears or fantasies about the treatment. They may feel that they are 'naughty' and may see it as a punishment. If they have been mistreated for most of their life, they will have much mistrust and very little hope of help. Siblings may have mentioned the word 'mad' in relation to coming for therapy and this can cause the child great anxiety. Sometimes they will have been given other explanations of the visit and are completely confused. These prior fantasies or explanations need to be explored by the therapist with the child. The major part of treatment is opening up clear lines of communication and openness, and dealing with fantasies so that the world makes sense to the child.

\section{General approach to sessions}

If the therapist asks themselves the following questions, he/she is far more likely to remain focused on what is important (see Box 3):

(a) What is the link between the end of the previous session and the beginning of this session?

(b) What is the affect or anxiety in this session?

(c) What is the relationship of this anxiety to:

(i) current preoccupations?

(ii) therapist?

(iii) childhood experiences?

(d) What is the theme of this session?

(e) What is the overall theme of the sessions?

\section{Box 3. General approach to sessions}

Links between sessions

The relationship between affect in the session to current preoccupation, the therapist and childhood experience

Themes and core conflicts in sessions

Contradictions, transference and countertransference as well as analysis of resistance. (f) What are this person's core conflicts?

(g) What are the contradictions in the person's material today?

(h) What are the transference and countertransference?

(i) What is the link between a dream and the transference (if relevant)?

(j) What is the resistance? (See Fitzgerald, 1988.)

\section{Conditions where psychotherapy has a role}

\section{Abuse}

One of the first tasks of healthy development is the acquisition of basic trust which will grow in the child in a good enough family. Children who are physically abused, sexually abused or suffer serious neglect, grow up very mistrustful and fearful of people. Child psychotherapy takes a very long time to reverse this mistrust of people, and an element of it probably always persists.

\section{Aggression}

Uncontrolled aggression in the classroom is a common reason for referral for child psychotherapy. Such children tend to have a history of being in a family where there was considerable violence, or have experienced violent attacks in or outside the family. There is often marital disharmony or alcoholism in the family. The child may be part of a very large family where the parents are overwhelmed by the excessive care-taking needs and not able to meet them. These experiences can leave children feeling very angry and resentful. They take these feelings out on other pupils or on the teacher in the classroom. In child psychotherapy, the child is helped to understand why they are so angry and aggressive and are helped to see the origins of their symptoms. The therapist helps the child to express feelings about experiences in earlier childhood and to understand them, and therefore to work through them and resolve them by talking about them so that they are not acted out.

\section{Anxiety}

A child may present with feelings of anxiety, nightmares, or fear of going out onto the street alone. This could be because he or she lives with 
extremely anxious, over-protective parents who are constantly worried about their welfare, telling them that the world is full of dangers and that all kind of catastrophes could happen. The child has nightmares of catastrophes, clings to his or her parents and is terrified of any separation from them. The child psychotherapist tries to help the child to see the world as a relatively safe place, and that there is not 'a catastrophe around every corner', which is an example of reality testing.

\section{Parasuicide}

Children from the age of about 12 years can commit or attempt suicide. For children who attempt suicide, child psychotherapy is required in addition to some other treatment like family therapy. It may be because the child is being abused in some way, or they may feel that they are not being treated well in the family and that some other sibling is being favoured. They may express their anger at someone close to them for not caring enough for them. The attempted suicide is then a way of punishing this person. The child psychotherapist helps the child to see that this is not an appropriate way of communicating with this other person and helps them to communicate in a more direct verbal fashion.

\section{Depression}

Childhood depression is not an uncommon presenting symptom. The father of a child (who was small in stature) was tall, athletic and had a very successful athletic career. The father was totally unaccepting of his son who was not athletic like himself. The father favoured another son who was athletic and fulfilled the father's ideal for a son. Clearly, in this case, work is required with both father and child. The child in psychotherapy had to be helped: to come to terms with his small stature and not to be so angry about it and to express anger directly to his father about his inappropriate attitude towards him. The father had to be helped to accept his son as he was.

In depressed children anger is usually turned inwards, and helping the child to express this anger outwards can be beneficial. The child has to be helped to value the assets that they have, as these can often get overlooked by the child when there is excessive focus on some negative issue, like short stature. The therapist must try to help the child to build up a positive self-image and increase their self-esteem.

Some children in families where there is marital violence blame themselves and feel inappropriately that it is caused by something in them that is 'bad'. The child psychotherapist helps the child to differentiate between that which they are responsible for and that which they are not.

\section{Abdominal pain}

A child complaining of tummy pain at $8 o^{\prime}$ clock each morning may do so because they inappropriately fear criticism from a teacher, or cannot face their own perfectionist academic standards. They may see it as a total disaster if they are not top of the class. The child experiences conflict which is then expressed as abdominal pain. The child psychotherapist helps the child to understand this pain and to modify their standards and to see the teacher as he or she is in reality.

\section{Effectiveness of child and adolescent psychotherapy}

This is of critical importance to psychotherapists, referrers and policy-makers (see Box 4). It is important because of the large numbers of children with emotional and conduct problems: one study of 200010 -year-olds found a rate of $16 \%$ (Fitzgerald, 1996). Clearly not all these would be candidates for psychodynamic psychotherapy. Psychodynamic child psychotherapy is one of the three most commonly used therapies, the other two being child behaviour modification and child cognitive therapy.

Some of the positive effects of psychotherapy are not seen immediately. Some of the improvements continue to arise between 18 months and three years after a child finishes psychotherapy treatment. For children, the overall improvement with psychotherapy has been put at between 67 and $78 \%$. The spontaneous improvement rate, that is the improvement rate without treatment, has been put at about 25\% (Kolvinet al, 1981). It is likely that child psychotherapy considerably speeds the rate of improvement.

The majority of scientific outcome studies are behavioural and only about $20 \%$ are nonbehavioural. Nine per cent of the studies used dynamic psychotherapy. A number of metaanalyses of controlled studies have been carried out. Weisz \& Weiss (1993) found a greater effect size for behavioural than non-behavioural treatments. Nevertheless, Shirk \& Russel (1992) have shown convincingly that it is erroneous for the wider scientific community to be under the impression that psychodynamic therapy has been shown to be 
Box 4. Effectiveness of child psychotherapy

Child psychotherapy is effective, with a 68 $78 \%$ improvement rate compared with a $25 \%$ spontaneous improvement rate. Intensity of treatment is associated with a better outcome. Children with disruptive disorders treated for three years or more had as good an outcome as those with emotional disorders.

less effective for children than the newer treatments. Eight per cent of the studies showed a negative effect of treatment. Effect sizes are similar in meta-analyses of child and adult psychotherapy. However, there are a number of limitations to meta-analytic studies, including problems with confounding variables and unrepresentativeness of many studies.

\section{Individual psychoanalytic studies}

The intensity of psychoanalytic treatment was found to be associated with a better outcome in a study of children with psychological problems, which has been replicated (Heinicke \& Ramsey Klee, 1986). At the end of treatment and at two years follow-up children treated four times a week showed greater improvement in self-esteem, adaptation and capacity for relationships than those treated only once a week.

Children with uncontrolled diabetes have shown significant improvement with psychoanalytic psychotherapy compared with an untreated control group (Moran et al, 1991).

A landmark study of child psychoanalysis of 763 cases showed

"child psychoanalysis to be particularly effective for seriously disturbed children under 12 years suffering from a variety of psychiatric disorders, particularly those which involve anxiety" (Fonagy \& Target, 1996).

Some of the aims of the treatment included replacing aggression and violence with a capacity to reflect on interpersonal experience and giving insight into current and earlier childhood experience. Other aims included giving the child 'developmental help', which means removing obstacles which have interfered with the normal emotional and cognitive development. These children show multiple symptomatology and features of borderline personality disorder. The transference and countertransference were used for the purpose of interpretation. Outcome was evaluated in terms of clinically significant change in overall adaptation using the Hampstead Child Adaptation Measure. Again, those treated four to five times per week showed greater improvement than those treated less frequently. Also, those having longer treatment showed greater improvement. Children with emotional disorder showed greater improvement than those with borderline personality disoder.

An important clinical finding in relation to adolescents was that they showed a high attrition rate and benefited as much from less intensive treatment. Indeed, Anna Freud favoured less intensive treatment for adolescents because it is important for adolescents to become independent from their parents and psychotherapy is dependence-inducing.

The findings with disruptive disorders are very important as they are very frequently referred for treatment (Fitzgerald, 1996). The study showed that when they were treated intensively for three years or more their outcome was as good as for those with emotional disorders. Depressed children were relatively resistant to psychotherapy and this finding is similar to the results of a previous study by Fitzgerald et al (1994). One of the major unsolved problems of child psychotherapy outcome research is that it is often effective in research studies but less effective in clinical situations. Fitzgerald (1996) has shown that an eclectic mixture of psychotherapy showed significant improvement in an out-patient child psychiatric clinic at three months follow-up, but that the positive effects had disappeared at one year follow-up.

In the years after treatment further 'booster' periods of psychotherapy may be needed as there is evidence that many forms of treatment may not have lasting effects (Fitzgerald, 1996).

\section{Conclusion}

While child psychotherapy has a considerable amount to offer to many disturbed children there is little doubt that some children will require multimodal treatments, for example, children with obsessional neurosis (Fitzgerald \& Berman, 1996). It is important for the psychotherapist to keep in mind that about $30 \%$ of the variance in relation to the aetiology of psychopathological problems will probably be explained by biological factors. A holistic approach is the only way that makes sense, with the therapist taking internal and external factors into account and keeping in mind a biopsychosocial model. 


\section{References}

American Psychiatric Association (1994) Diagnostic and Statistical Manual of Mental Disorders (4th edn) (DSM-IV). Washington, DC: APA.

Berman, D., Fitzgerald, M. \& Hayes, J. (eds) (1996) The Danger of Words. Bristol: Thoemmes Press.

Cohler, B. J. \& Galatzer-Levy, R. (1988) Self psychology and psychoanalytic psychotherapy. In New Concepts in Psychoanalytic Psychotherapy (eds J. M. Ross \& W. Myers), pp. 204-225. Washington, DC: American Psychiatric Press.

Fitzgerald, M. (1988) The technique of analyticpsychotherapy. Journal of Irish Forum for Psychoanalytic Psychotherapy, 1, 34-44.

(ed.) (1996) Irish Families Under Stress, Vol. 5. Dublin: EHB

- \& Berman, D. (1996) Obsessive-compulsive disorder in the 1990's. Irish Journal of Child and Adolescent Psychotherapy, 1, 65-74.

-, Jeffers, A. \& Kinsella, A. (1994) A follow up study of depressive illness in childhood. British Journal of Clinical Social Psychiatry, 9,12-15.

Fonagy, P. \& Target, M. (1996) Predictors of outcome in child psychoanalysis; A retrospective of 763 cases at the Anna Freud Centre. Journal of the American Psychoanalytic Association, 44, 27-78.

Freud, A. (1965) Normality and Pathology in Childhood. The Writings, Vol. 6. New York: International University Press.

- (1974) Introduction to Psychoanalysis. London: Hogarth.

Heinicke, C. M. \& Ramsey Klee, D. M. (1986) Outcome of child psychotherapy, as a function of frequency obsessions. Journal American Academy of Child Psychiatry, 25, 247-253.

Klein, M. (1932) The Psychotherapy of Children. London: Hogarth.

Kolvin, I., Garside, R., Nicol, A., et al (1981) Help Starts Here. London: Tavistock.

Mayes, L. C. \& Cohen D. J. (1996) Children's developing theory of mind. Journal of the American Psychoanalytic Association, 44, $117-142$.

Moran, G. S., Fonagy P., Kurtz, A., et al (1991) A control study of psychoanalytic treatment of brittle diabetes. Journal American Academy of Child Psychiatry, 30, 241-257.

Sandler, J., Kennedy, H. \& Tyson, R. (1980) The Technique of Child Psychoanalysis. London: Hogarth.

Segal, H. (1981) The Work of Hanna Segal. New York: Jason Aronson

Shirk, S. R. \& Russel, R. C. (1992) A reevaluation of estimates of child therapy effectiveness. Journal American Academy of Child and Adolescent Psychiatry, 31, 703-709.

Weisz, J. R. \& Weiss, B. (1993) Effects of Psychotherapy with Children and Adolescents. London: Sage.

Yanof, J. A. (1996) Child analysis: language, communication, transference. Journal American Psychoanalytic Association, 44, 79-116.

\section{Multiple choice questions}

1. Child psychoanalytic psychotherapy would not be considered as a major choice of therapy for which of the following?
a autism
b anxiety disorder
c depressive disorder
d grief reaction
e disruptive disorders.

2. The following would be a generally accepted spontaneous improvement rate:
a $95 \%$
b $80 \%$
c $75 \%$
d $25 \%$
e $50 \%$.

3. Which of the following is not a key concept of psychoanalysis:
a transference
b countertransference
c working through
d conditioning
e unconscious

4. Which of the following women were not associated with child psychotherapy:
a Anna Freud
b Melanie Klein
c Hermine Hug-Hellmuth
d Elizabeth Malcolm
e Margaret Mahler.

\begin{tabular}{|c|c|c|c|}
\hline \multicolumn{4}{|c|}{ MCQ answers } \\
\hline 1 & 2 & 3 & 4 \\
\hline a $\mathrm{T}$ & a $F$ & a $F$ & a $F$ \\
\hline b F & b F & b F & b F \\
\hline c $\mathrm{F}$ & c $F$ & c $\mathrm{F}$ & c $\mathrm{F}$ \\
\hline d F & d $T$ & d $\mathrm{T}$ & d \\
\hline e $F$ & e $F$ & e $F$ & e $F$ \\
\hline
\end{tabular}

